\title{
Time-series analysis of gene expression profiles induced by nitrosamides and nitrosamines elucidates modes of action underlying their genotoxicity in human colon cells
}

Citation for published version (APA):

Hebels, D. G. A. J., Brauers, K. J. J., van Herwijnen, M. H. M., Georgiadis, P. A., Kyrtopoulos, S. A., Kleinjans, J. C. S., \& de Kok, T. M. C. M. (2011). Time-series analysis of gene expression profiles induced by nitrosamides and nitrosamines elucidates modes of action underlying their genotoxicity in human colon cells. Toxicology Letters, 207(3), 232-241. https://doi.org/10.1016/j.toxlet.2011.09.012

Document status and date:

Published: 15/12/2011

DOI:

10.1016/j.toxlet.2011.09.012

Document Version:

Publisher's PDF, also known as Version of record

Document license:

Taverne

Please check the document version of this publication:

- A submitted manuscript is the version of the article upon submission and before peer-review. There can be important differences between the submitted version and the official published version of record. People interested in the research are advised to contact the author for the final version of the publication, or visit the DOI to the publisher's website.

- The final author version and the galley proof are versions of the publication after peer review.

- The final published version features the final layout of the paper including the volume, issue and page numbers.

Link to publication

\footnotetext{
General rights rights.

- You may freely distribute the URL identifying the publication in the public portal. please follow below link for the End User Agreement:

www.umlib.nl/taverne-license

Take down policy

If you believe that this document breaches copyright please contact us at:

repository@maastrichtuniversity.nl

providing details and we will investigate your claim.
}

Copyright and moral rights for the publications made accessible in the public portal are retained by the authors and/or other copyright owners and it is a condition of accessing publications that users recognise and abide by the legal requirements associated with these

- Users may download and print one copy of any publication from the public portal for the purpose of private study or research.

- You may not further distribute the material or use it for any profit-making activity or commercial gain

If the publication is distributed under the terms of Article 25fa of the Dutch Copyright Act, indicated by the "Taverne" license above,

Download date: 26 Apr. 2023 


\title{
Time-series analysis of gene expression profiles induced by nitrosamides and nitrosamines elucidates modes of action underlying their genotoxicity in human colon cells
}

\author{
Dennie G.A.J. Hebels ${ }^{a}{ }^{*}$, Karen J.J. Brauers ${ }^{a}$, Marcel H.M. van Herwijnen ${ }^{a}$, Panagiotis A. Georgiadis ${ }^{b}$, \\ Soterios A. Kyrtopoulos ${ }^{b}$, Jos C.S. Kleinjans ${ }^{a}$, Theo M.C.M. de Kok ${ }^{a}$ \\ a Department of Toxicogenomics, Maastricht University, PO Box 616, 6200 MD Maastricht, The Netherlands \\ ${ }^{\mathrm{b}}$ National Hellenic Research Foundation, Institute of Biological Research and Biotechnology, 48 Vas Constantinou Avenue, Athens 11635 , Greece
}

\section{A R T I C L E I N F O}

\section{Article history:}

Received 8 June 2011

Received in revised form

13 September 2011

Accepted 14 September 2011

Available online 19 September 2011

\section{Keywords:}

Toxicogenomics

$\mathrm{N}$-nitroso compounds

Time-series

Alkylating agents

$\mathrm{O}^{6}$-methylguanine

Colon carcinogenesis

\begin{abstract}
A B S T R A C T
$\mathrm{N}$-nitroso compounds (NOCs) may represent a carcinogenic risk to humans following endogenous colonic nitrosation processes. We used the colon adenocarcinoma cell line Caco-2 to investigate transcriptomic changes at three time points $(1,6,24 \mathrm{~h})$ following exposure to genotoxic concentrations of six different NOCs (two nitrosamides, four nitrosamines) with the purpose of identifying biological processes that may play a part in the carcinogenicity of these compounds. This is especially important for nitrosamide exposure where, in light of their high reactivity, important gene expression modifications may take place early in the exposure. We also analyzed NOC-induced $\mathrm{O}^{6}$-methylguanine adducts in relation to transcriptomics since these adducts may influence the expression of genes pivotal in NOC-associated carcinogenicity. Many modified pathways appeared related to DNA damage, cell cycle, apoptosis, growth factor signaling and differentiation, which are linked with carcinogenicity. Nitrosamides showed the strongest response at $1 \mathrm{~h}$ of exposure, while nitrosamines had the strongest effect at 6 and $24 \mathrm{~h}$. Additionally, methylation was strongly associated with processes that may contribute to the carcinogenic risk. In summary, we have found that NOC-induced gene expression changes vary over time and that many of the modified pathways and processes indicate a carcinogenic risk associated with NOC exposure.
\end{abstract}

(c) 2011 Elsevier Ireland Ltd. All rights reserved.

\section{Introduction}

$\mathrm{N}$-nitroso compounds (NOCs) have long been recognized as genotoxic and carcinogenic agents in animal models and therefore may also be implicated in human carcinogenesis (Lijinsky, 1992). The gastro-intestinal tract seems to be a particularly relevant target since NOCs are known to occur in certain types of food, such as beer, fish and nitrite-preserved meat (Tricker and Preussmann, 1991). More importantly, endogenous nitrosation of NOC precursors, particularly in the stomach and colon, can significantly increase the colonic NOC exposure (Kuhnle and Bingham, 2007; Mirvish, 1995). The endogenous formation of NOCs may also explain the link between meat consumption and colorectal

Abbreviations: CCR, colorectal cancer; GEO, Gene Expression Omnibus; MIF, macrophage migration inhibitory factor; MNNG, N-methyl-N'-nitro-Nnitrosoguanidine; MNU, N-methyl-N-nitrosurea; NDEA, N-nitrosodiethylamine; NDMA, N-nitrosodimethylamine; NOCs, N-nitroso compounds; NPIP, Nnitrosopiperidine; NPYR, N-nitrosopyrrolidine; $\mathrm{O}^{6}$-meG, $\mathrm{O}^{6}$-methylguanine; PCA, principal component analysis; TGF- $\beta$, transforming growth factor beta.

* Corresponding author. Tel.: +31 43 3881088; fax: +31 433884146.

E-mail address: d.hebels@maastrichtuniversity.nl (D.G.A.J. Hebels). cancer (CRC) risk since CRC incidence rates are correlated with average meat consumption levels (Larsson and Wolk, 2006; Norat et al., 2002) and meat consumption results in increased levels of endogenous nitrosation (Kuhnle and Bingham, 2007). To investigate the possible role of NOCs in human colon carcinogenesis, we previously explored the transcriptomic effects of genotoxic NOC concentrations following a $24 \mathrm{~h}$ exposure in the human colon adenocarcinoma cell line Caco-2 (Hebels et al., 2009). We distinguished between two main classes of NOCs, nitrosamines and nitrosamides. An interesting observation was the absence of strong gene expression effects following nitrosamide exposure. Since nitrosamides, in contrast to nitrosamines, can decompose without the need for metabolization to form genotoxic intermediates, particularly alkylating diazonium ion species, we hypothesize that modifications in critical molecular processes may occur earlier in the exposure period. Furthermore, although the alkylating potential of NOCs has been studied extensively and the role of alkylation in the carcinogenic process is well documented (Hall and Montesano, 1990; Kaina et al., 2007; Shrivastav et al., 2010), it is of interest to analyze gene expression changes associated with NOC-induced alkylation over time. Alkylation of DNA, and methylation in particular, has previously been linked to the modulation of gene 
expression. For example, $\mathrm{O}^{6}$-methylguanine $\left(\mathrm{O}^{6}-\mathrm{meG}\right)$ has been shown to both inhibit and promote the action of maintenance methylases on adjacent cytosine bases which is likely to result in chromatin modifications that can influence the level of gene transcription (Hepburn et al., 1991; Tan and Li, 1990). In addition, $\mathrm{O}^{6}-\mathrm{meG}$ can inhibit transcription factor binding (Bonfanti et al., 1991; Gray, 1995). Investigating methylation-associated gene expression changes could thus lead to the identification of critical pathways which may underlie the carcinogenic mechanism of action of methylating agents.

In order to establish time-dependent gene expression responses, we analyzed genome-wide gene expression in Caco2 cells exposed at 1,6 and $24 \mathrm{~h}$ to comparably genotoxic concentrations of 2 different nitrosamides (N-methyl- $\mathrm{N}^{\prime}$ nitro-N-nitrosoguanidine [MNNG] and $\mathrm{N}$-methyl-N-nitrosurea [MNU]) and 4 nitrosamines (N-nitrosodiethylamine [NDEA], Nnitrosodimethylamine [NDMA], N-nitrosopiperidine [NPIP], and $\mathrm{N}$-nitrosopyrrolidine [NPYR]). These NOCs can be formed in the gastro-intestinal tract (Sen et al., 2000; Tricker and Preussmann, 1991) and induce malignant transformation of human colonic epithelial cells (Paraskeva et al., 1990). We identified cellular processes that were modified over time by these NOCs, and applied separate per time point analysis to determine at what time points relevant pathways or cellular processes were most strongly modulated. Individual gene expression data were linked with levels of apoptosis and cell cycle distribution as phenotypic markers of effect to functionally anchor gene sets differentially modified by NOC exposure. To investigate the gene expression modulations associated with methylation, we further explored the transcriptomic response of the three methylating NOCs (MNNG, MNU, and NDMA). To do this, we correlated gene expression levels with $\mathrm{O}^{6}$-meG adduct levels, one of the most frequently occurring pre-mutagenic DNA lesions found after exposure to methylating agents (Kyrtopoulos, 1998), and analyzed the correlating gene set for involvement in pathways or cellular processes. Our overall goal is to establish a transcriptomic overview of NOC-induced and methylation-associated responses at a biological pathway level over time that can be used for further analysis on the carcinogenic potential of these compounds.

\section{Materials and methods}

\subsection{Cell culture}

The human colon adenocarcinoma cell line Caco-2 was cultured in Dulbecco's Modified Eagle's Medium (Sigma-Aldrich, Zwijndrecht, The Netherlands) with $4.5 \mathrm{~g} / \mathrm{L}$ glucose, L-glutamine, $\mathrm{NaHCO}_{3}$ and pyridoxine $\mathrm{HCl}$ supplemented with $1 \%$ $(\mathrm{v} / \mathrm{v})$ nonessential amino acids, $1 \% \mathrm{Na}$-pyruvate, $1 \%$ penicillin/streptomycin and $10 \%$ (v/v) heat-inactivated foetal calf serum, all purchased from Gibco BRL (Breda, The Netherlands). Cell cultures were transferred weekly by trypsinization and incubated at $37{ }^{\circ} \mathrm{C}$ in a humidified incubator containing $5 \% \mathrm{CO}_{2}$.

\subsection{Treatment and isolation of cells}

Caco-2 cells were treated with MNNG, MNU, NDEA, NDMA, NPIP or NPYR or the corresponding solvent control (MilliQ or DMSO, final concentration $0.1 \%$ ) at comparably genotoxic concentrations, as established previously by comet assay analysis (Hebels et al., 2009). These concentrations were: MNNG (1 $\mu \mathrm{M})$, MNU (1 mM), NDEA (50 mM), NDMA (100 mM), NPIP ( $40 \mathrm{mM})$ and NPYR (100 mM). Exposures were carried out in 25 or $75 \mathrm{~cm}^{2}$ culture flasks for 1,6 or $24 \mathrm{~h}$. All NOCs were obtained from Sigma-Aldrich (the respective product numbers and reported purity were: 15427LO [97\%], N4766 [11\% $\mathrm{H}_{2} \mathrm{O}, 3 \%$ acetic acid], N0756, N7756, N6007 [99.8\%], and 158240 [98.9\%]). Experiments were carried out in duplicate. Cells were isolated by trypsinization and washed in PBS and subsequently stored at $-20^{\circ} \mathrm{C}$ (for methylation assay) or fixed in methanol and stored at $-20^{\circ} \mathrm{C}$ (for flow cytometry). Cells for microarray experiments were isolated with TRIzol ${ }^{\circledR}$ Reagent (Invitrogen, Breda, The Netherlands) and stored at $-20^{\circ} \mathrm{C}$. Viability of cells was determined with the MTT test in ELISA plates (Greiner Bio-One, Alphen a/d Rijn, The Netherlands) as described by Mosmann (1983). All exposures resulted in $>90 \%$ viability.

\subsection{Immunocytochemistry and flow cytometric analysis}

Methanol-fixed cells were indirectly stained for cleaved cytokeratin 18 (an early sign of apoptosis) using the primary antibody M30 CytoDeath (Roche, Penzberg, Germany) and subsequently analyzed by flow cytometric analysis using a FACSort (Becton Dickinson, Sunnyvale, USA) as described by Schutte et al. (2006). Data analysis was performed as described previously (Hebels et al., 2009).

\subsection{Determination of $0^{6}-m e G$ in DNA by ELISA}

Levels of $\mathrm{O}^{6}$-meG were determined in DNA isolated from NOC-exposed Caco-2 cells using a newly developed ELISA method as recently described by Georgiadis et al. (2011). DNA samples were analyzed in triplicate. For the quantitation of $\mathrm{O}^{6}-\mathrm{meG}$ in unknown DNA samples, a standard curve consisting of DNA standards with known $\mathrm{O}^{6}$-meG content was constructed with each microwell plate. These standards were prepared by mixing HeLa DNA, methylated with MNU and accurately analyzed by HPLC ( $\mathrm{O}^{6}$-meG content: 1 adduct/13,000 nucleotides), with unmodified HeLa DNA extracted from $\mathrm{O}^{6}$-meG-DNA methyltransferase-overexpressing cells as described previously (Georgiadis et al., 2000).

\subsection{Microarray hybridization and data analysis}

Microarray hybridization was performed as described previously (Hebels et al., 2009). In short, RNA was isolated from QIAzol $^{\circledR}$ suspended cells, following a 1 6 or 24 h exposure to comparably genotoxic NOC concentrations (two biological replicates) and dye-labeled cRNA (Cy3 or Cy5) was synthesized. Samples were hybridized on Agilent $4 \times 44 \mathrm{~K}$ Whole Human Genome microarrays (Agilent Technologies, Amstelveen, The Netherlands) against their vehicle control, applying a dye-swap between the biological replicates.

After scanning the microarray slides, using settings described before (Hebels et al., 2009), the data was flagged manually and automatically using the GenePix Pro software (version 6.0, Molecular Devices, Sunnyvale, CA). Following a quality control in the statistical software environment $\mathrm{R}$ (version 2.10.1, The R Foundation for Statistical Computing, Vienna, Austria), regions of lower quality were identified and subsequently flagged in Spotfire DecisionSite (version 9.1, TIBCO, Somerville, MA). LOWESS normalization and subsequent data analysis was performed in ArrayTrack (version 3.4, NCTR, Jefferson, AR). The expression difference for each spot was calculated by subtracting the $\log 2$ transformed mean intensity of the control sample from the $\log 2$ transformed mean intensity of the treated sample resulting in a $\log 2$ ratio.

Differentially expressed genes were selected by using a combined filtering on significance level and $\log 2$ ratio as proposed by Shi et al. (2006). ArrayTrack was used to select differentially expressed genes based on a two-tailed Student's $t$-test ( $p$-value $<0.05$ ), with a minimum absolute $\log 2$ ratio of 0.5 for each compound and time point (false discovery rates were all below $20 \%$ ). These genes were subsequently imported in MetaCore ${ }^{\mathrm{TM}}$ (GeneGo, San Diego, CA). MetaCore ${ }^{\mathrm{TM}}$ is an online software suite that identifies and visualizes the involvement of differentially expressed genes in specific cellular pathways, which is subsequently related to the total number of genes involved in the particular pathway and in all the available pathways combined. This results in a set of significantly modulated pathways ( $p$-value $<0.05$ ).

The online software suite GenePattern version 3.1 (http://www.broad.mit.edu/cancer/software/genepattern/) was used for principal component analysis (PCA) of the tested compounds. PCA plots were generated in GenePattern by reducing the data to two dimensions and visualized in Microsoft Excel. Time-course effects were further investigated, by ANOVA analysis in ArrayTrack to determine which genes changed their expression profile significantly over time. These genes were also analyzed in MetaCore to determine their involvement in pathways.

Gene expression data were subsequently used to perform Spearman's rank correlation analyses with levels of apoptosis, cell cycle phase distribution, and $\mathrm{O}^{6}$-meG levels using the online Gene Expression Profile Analysis Suite (http://gepas.bioinfo.cipf.es/). Significantly correlating genes ( $p$-value $<0.05$ ) were subsequently further analyzed in MetaCore.

The gene expression data discussed in this publication have been deposited in NCBI's Gene Expression Omnibus (GEO) and are available through GEO series accession number GSE20993 (http://www.ncbi.nlm.nih.gov/ geo/query/acc.cgi?acc=GSE20993).

\section{Results}

\subsection{Time-course analysis: PCA and ANOVA}

In order to investigate the transcriptomic effects of NOCs over time we performed whole genome microarray analysis at three time points for each of the six selected NOC, and PCA plots were generated to visualize the differences in gene expression profiles. The three non-methylating NOCs (NDEA, NPIP, and NPYR) show a similar response compared to each other, and simultaneously 


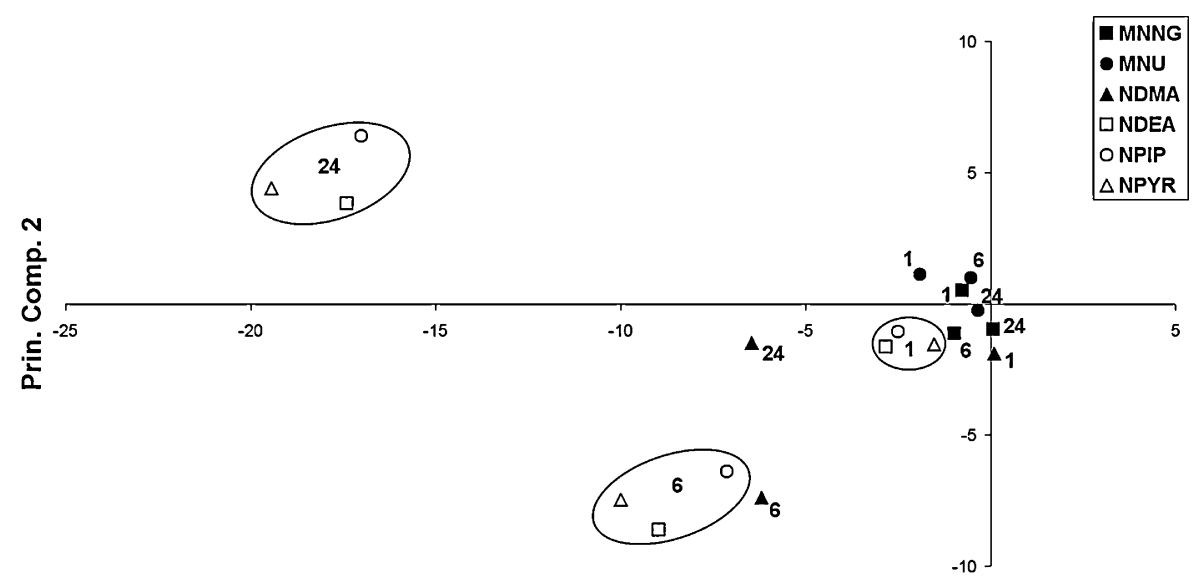

Prin. Comp. 1

Fig. 1. PCA plot based on genes present for all NOCs at three time points. The percentage variation for principal components 1 and 2 were 61.06 and $14.83 \%$.

demonstrate a time-dependent development of the gene expression response (Fig. 1). Although NDMA is closely associated with these nitrosamines at $6 \mathrm{~h}$ of exposure, it shows a different response after $24 \mathrm{~h}$, which we also found in our previous study (Hebels et al., 2009). To look at each individual time point in more detail, PCA plots were also generated per time point (Suppl. Figs. A.1-A.3). While these plots show a similar pattern as Fig. 1, they also reveal that MNU and MNNG respond differently at each time point. In accordance with the number of significantly modulated genes and pathways, MNU develops the most differentiating response at $1 \mathrm{~h}$ of exposure, while MNNG generates such a response at $6 \mathrm{~h}$. After $24 \mathrm{~h}$ of exposure both nitrosamides are grouped closely to the origin of the plot indicating little effect.

The time-course development of the gene expression profile was further investigated using an ANOVA analysis to determine which cellular processes contribute most to the changes in expression profile over time. In Table 1 , an overview of processes for each of the six compounds found by MetaCore analysis is presented. In Suppl. Table A.1, a more comprehensive overview can be found which includes the names of the GeneGO pathways modified in each of the cellular processes. Amino acid metabolism, apoptosis and survival, and cystic fibrosis are significantly modified over time by all compounds, except MNU. The development, $\mathrm{G}$-protein signaling, and immune response processes are modified by all six compounds and are likely to play an important part in the time-course development of the gene expression profile, especially since the number of pathways involved in these processes is, overall, relatively high. Other strongly modified processes comprise cell cycle, steroid metabolism, and transcription. When comparing the nitrosamide and nitrosamine-induced time-dependent changes, in general, more processes and pathways seem to be modified over time during nitrosamine exposure. The percentages of involved genes are also higher for the nitrosamine group, which is in agreement with the PCA plots. The Venn diagram in Fig. 2A shows the overlap between the two nitrosamides and the nitrosamines as a group. MNNG and MNU uniquely change the expression of a considerable number of pathways over time. For MNNG these pathways are mainly involved in apoptosis and survival, glutathione metabolism, G-protein signaling and immune response, while for MNU cell cycle, development, and DNA damage responses are mainly affected (Suppl. Table A.2). The pathways uniquely modified by the nitrosamines are involved in similar processes but often regulate different parts of the process. For example, the apoptosis and survival pathways include different signaling cascades and several development pathways are involved in transforming growth factor beta (TGF- $\beta$ ) signaling. There are also a number of
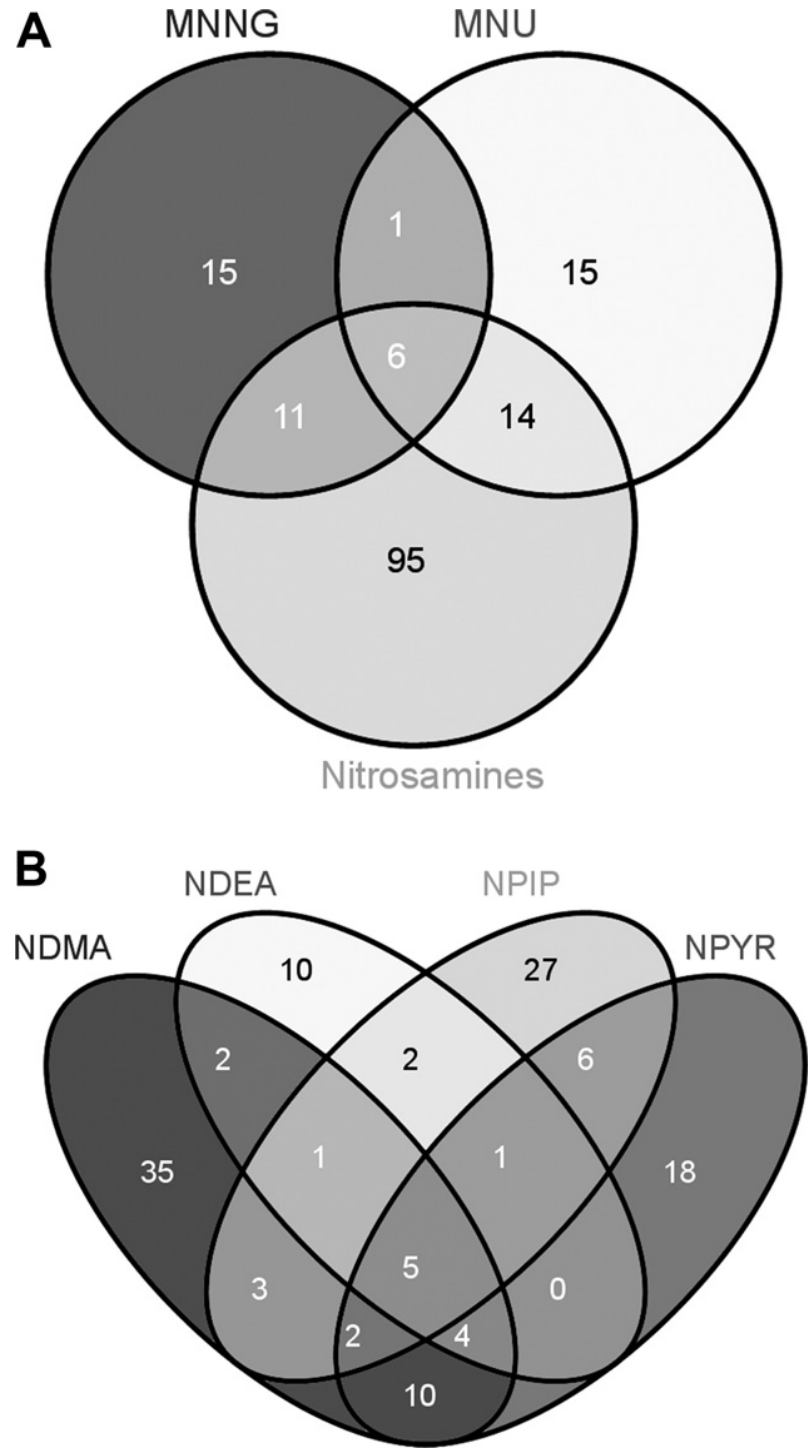

Fig. 2. Venn diagrams showing the number of overlapping ANOVA pathways between MNNG, MNU, and the nitrosamines as a group (A) and between the four individual nitrosamines (B). 
Table 1

MetaCore analysis of ANOVA data resulting in the identification of cellular processes modified over time for each NOC following exposure at genotoxic concentrations.

\begin{tabular}{|c|c|c|c|c|c|c|}
\hline Cellular process & MNNG & MNU & NDMA & NDEA & NPIP & NPYR \\
\hline Amino acid metabolism & $5(30)$ & & $2(48)$ & $4(56)$ & $1(56)$ & $5(78)$ \\
\hline Apoptosis and survival & $3(26)$ & & $12(52)$ & $5(44)$ & $3(48)$ & $8(63)$ \\
\hline Butanoate metabolism & & & & & $1(55)$ & \\
\hline Cell adhesion & & & & & $2(62)$ & \\
\hline Cell cycle & $1(25)$ & $11(38)$ & $8(55)$ & & $1(50)$ & $7(68)$ \\
\hline Cystic fibrosis & $1(26)$ & & $1(65)$ & $1(53)$ & $4(68)$ & 2(69) \\
\hline Cytoskeleton remodeling & & $1(20)$ & & & $2(52)$ & \\
\hline Development & $2(26)$ & $9(28)$ & 13(49) & $2(49)$ & $7(48)$ & $3(61)$ \\
\hline DNA damage & $1(24)$ & $3(34)$ & $5(54)$ & $1(46)$ & & \\
\hline Folic acid metabolism & & & $1(60)$ & & & \\
\hline Fructose metabolism & & $2(26)$ & $2(49)$ & & & \\
\hline Galactose metabolism & & & & & $2(59)$ & $1(69)$ \\
\hline Glutathione metabolism and oxidative stress & $3(21)$ & & $1(67)$ & & & $1(78)$ \\
\hline Glycolysis and gluconeogenesis & & & $1(60)$ & $1(53)$ & $2(57)$ & $1(67)$ \\
\hline G-protein signaling & $2(49)$ & $1(36)$ & $2(52)$ & $1(50)$ & $1(56)$ & $2(65)$ \\
\hline Heme metabolism & & & & & $1(48)$ & \\
\hline Immune response & $10(31)$ & $6(31)$ & $4(55)$ & $3(58)$ & $7(54)$ & $1(67)$ \\
\hline Neurodisease & & & & & & $1(72)$ \\
\hline Neurophysiological process & & & $1(58)$ & $1(58)$ & & \\
\hline N-glycan biosynthesis & & & & $1(47)$ & & \\
\hline Nucleotide metabolism & & & $2(53)$ & & & $2(53)$ \\
\hline Oxidative phosphorylation & & & & $1(37)$ & $1(46)$ & $1(54)$ \\
\hline Propionate metabolism & & & & & & $1(62)$ \\
\hline Proteolysis & & & & & $1(58)$ & $1(86)$ \\
\hline Regulation of lipid metabolism & $1(3)$ & & $1(67)$ & & $1(67)$ & $1(65)$ \\
\hline Reproduction & & $1(21)$ & & & & \\
\hline Signal transduction & & $1(26)$ & & & $1(48)$ & $1(59)$ \\
\hline Steroid metabolism & $1(29)$ & & $2(56)$ & $3(57)$ & $2(68)$ & 2(69) \\
\hline Sulfur metabolism & $1(39)$ & & & $1(50)$ & $1(56)$ & \\
\hline Transcription & $1(23)$ & $1(26)$ & $3(50)$ & & $3(55)$ & $2(67)$ \\
\hline Transport & $1(20)$ & & $1(42)$ & & & $2(66)$ \\
\hline Tricarboxylic acid cycle & & & & & $1(56)$ & \\
\hline Ubiquinone metabolism & & & & & $1(46)$ & $1(64)$ \\
\hline Urea cycle & & & & & $1(52)$ & \\
\hline
\end{tabular}

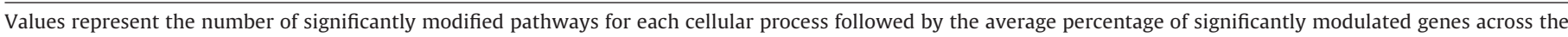
three time points in these pathways. Absence of a value means that the cellular process was not differentially modified over time for that particular compound.

pathways involved in processes not modified by nitrosamides, such as nucleotide metabolism and several other metabolic pathways. The Venn diagram in Fig. 2B shows that within the nitrosamine group, a total of 35 pathways are uniquely modified by NDMA, which includes a number of pathways involved in apoptosis and survival, cell cycle regulation, development, and DNA damage (Suppl. Table A.3).

\subsection{Transcriptomic analysis per time point}

To investigate transcriptomic changes per time point for each compound, significantly modulated genes ( $p$-value $<0.05)$ with a minimum absolute $\log 2$ ratio of 0.5 were selected and subsequently used for a pathway analysis in MetaCore. An overview of the cellular processes modified by each of the six compounds per time point and a more comprehensive overview, which includes the names of the GeneGO pathways modified in each of the cellular processes, is presented in Suppl. Tables A.4-A.7. The percentage of significantly modulated genes in each of the pathways and the average per process is also presented there. A total of 39 cellular processes was found to be modified by at least one of the compounds and for most processes the percentage of involved genes for the associated pathways increases with time. Some of the processes most strongly represented include apoptosis and survival, cell cycle, cytoskeleton remodeling, development, DNA damage, G-protein signaling, immune response, regulation of lipid metabolism, and transcription. Although some cellular processes are significantly modulated by the same compound at all three time points, most only come up once or twice. The development and immune response processes are present at every time point for nearly every compound. Cell cycle and DNA damage processes, on the other hand, are mostly modified at $6 \mathrm{~h}$. To visualize the changes over time, the total number of pathways per condition for all processes combined is shown in Fig. 3, with the total average of involved genes. The percentage of involved genes stays relatively constant over time for the nitrosamides. The number of pathways, however, is highest at $1 \mathrm{~h}$ of exposure for both nitrosamides and MNU even shows the highest number of pathways of all NOC across all time points. Although the nitrosamines modulate different numbers of pathways across time and also influence many pathways at $1 \mathrm{~h}$, the average percentage of genes involved in these pathways is highest at 6 and $24 \mathrm{~h}$. Overall, the nitrosamides appear to induce the strongest response at $1 \mathrm{~h}$, while the nitrosamines tend to have the most pronounced effects at later time points.

\subsection{Apoptosis and cell cycle distribution correlation analyses}

We subsequently associated gene expression data from all time points and compounds with levels of apoptosis and cell cycle distribution as phenotypic markers of effect to functionally anchor gene sets differentially modified by NOC exposure over time. Levels of apoptosis and effects on cell cycle distribution are shown in Fig. 4A and $\mathrm{B}$, respectively. The nitrosamines show a timedependent increase in the level of apoptosis, although this increase is only significantly different from control conditions at the $24 \mathrm{~h}$ nitrosamine exposure. Cell cycle distribution after $24 \mathrm{~h}$ of exposure was significantly affected by all compounds, except MNNG. At earlier time points, no effects were observed compared to control distribution. MNU, NDEA, NPIP, and NPYR exposure resulted in an S-phase accumulation of cells, which for MNU, NPIP, and NPYR was also associated with a decrease in G1-phase cells, while NDEA shows a concomitant decrease in G2-phase cells. NDMA exposure 


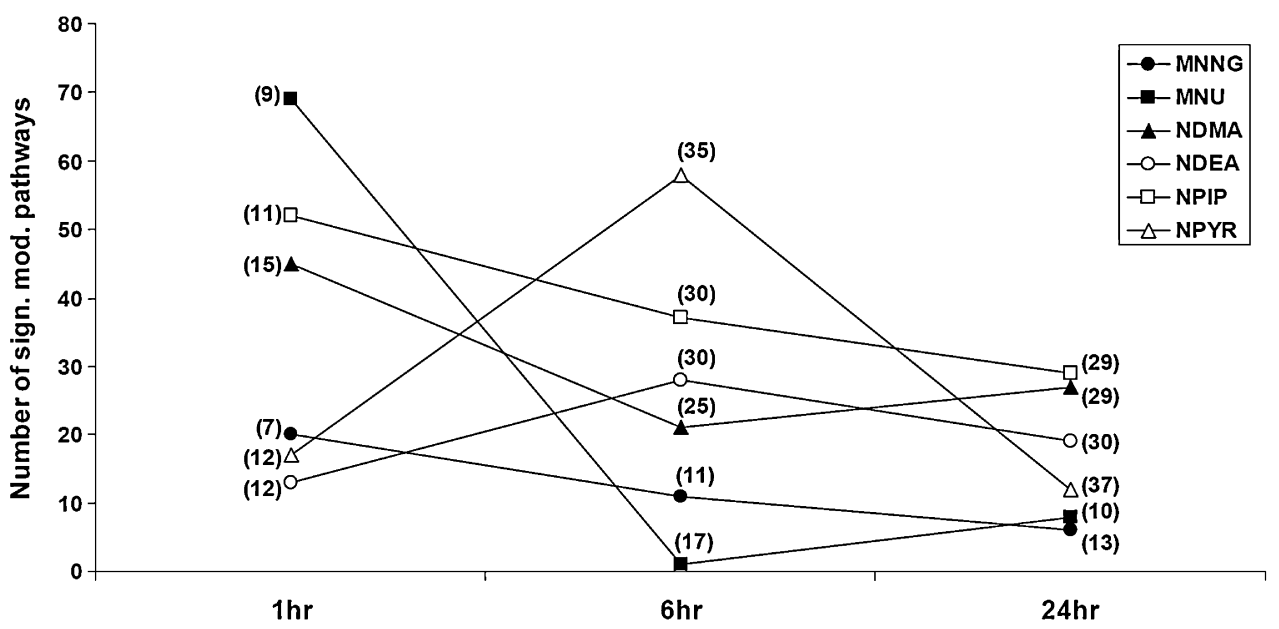

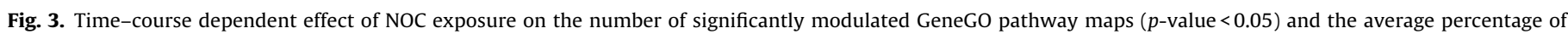
significantly modulated genes involved in these pathways per condition (between brackets).

results in a G1-phase accumulation of cells and a decreased S-phase distribution.

Genes significantly correlating with the level of apoptosis or cell cycle phase distribution ( $p$-value $<0.05$ ) across all time points and compounds were used for a pathway analysis in MetaCore. As shown in Table 2, these genes are indeed involved in apoptosis and cell cycle related cellular processes. A complete overview of correlating processes can be found in Suppl. Table A.8.
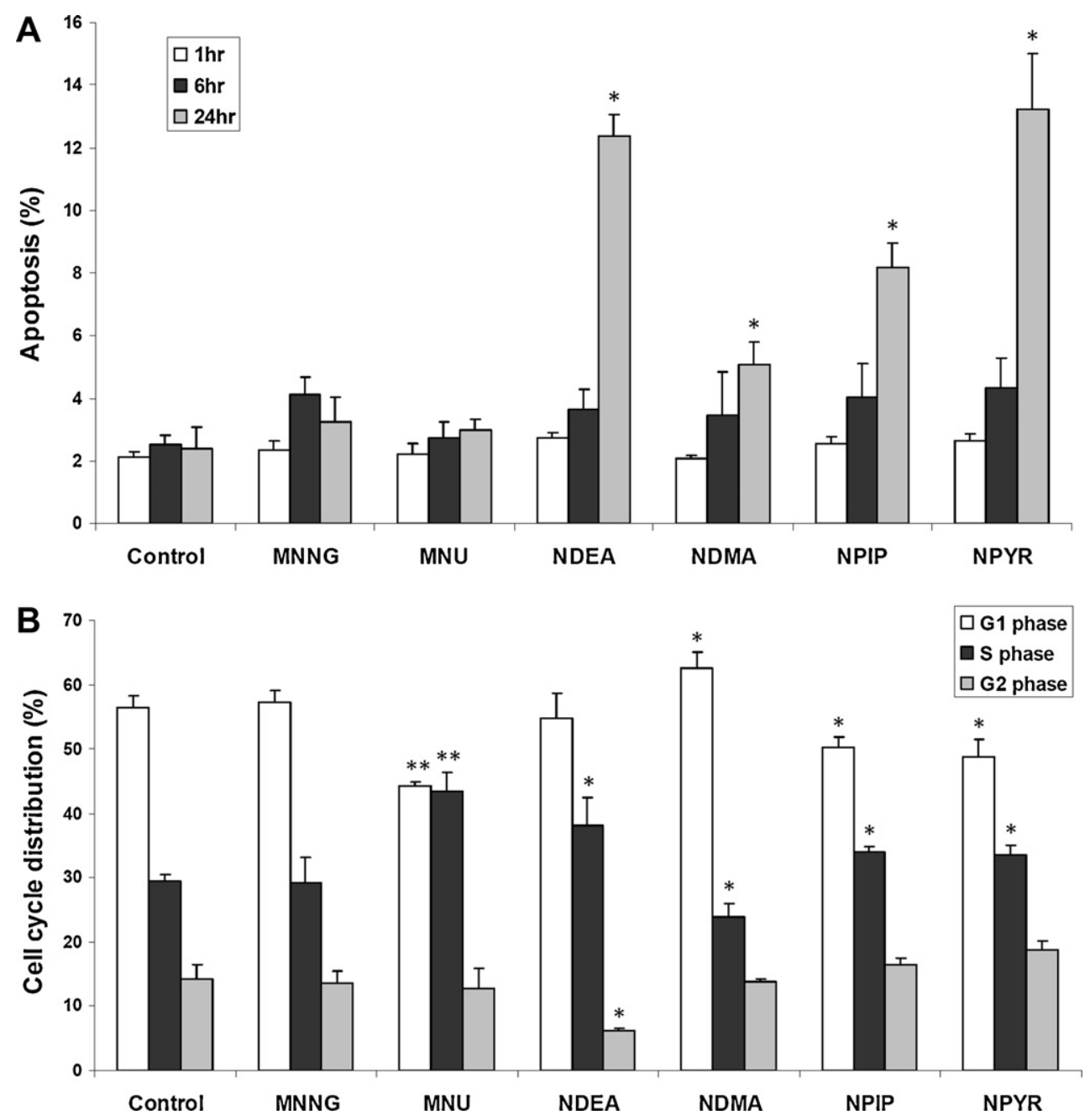

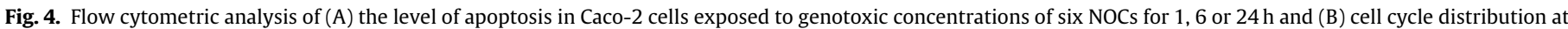

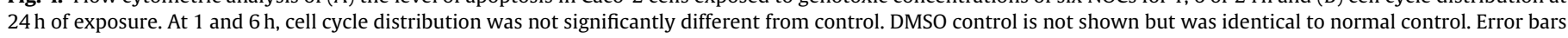
indicate standard deviation. Student's $t$-test versus control: ${ }^{*} p$-value $<0.05 ;{ }^{* *} p$-value $<0.01$. 
Table 2

Selection of cellular processes correlated with apoptosis and cell cycle phase distribution as found by MetaCore analysis.

\begin{tabular}{|c|c|c|c|c|c|c|}
\hline \multirow[t]{2}{*}{ Phenotypical marker } & \multicolumn{6}{|l|}{ Cellular process } \\
\hline & Apoptosis and survival & Cell adhesion & Cell cycle & Cytoskeleton remodeling & Nucleotide metabolism & Proteolysis \\
\hline Apoptosis & $7(67)$ & $3(68)$ & $2(68)$ & $2(66)$ & $5(68)$ & $2(72)$ \\
\hline G1-phase & & $1(50)$ & $1(33)$ & & & \\
\hline S-phase & & & $1(27)$ & & $1(17)$ & \\
\hline G2-phase & & $2(19)$ & $1(21)$ & $2(19)$ & & \\
\hline
\end{tabular}

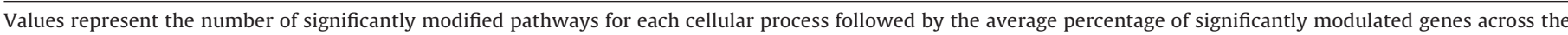
three time points and six compounds in these pathways.

\section{4. $0^{6}-m e G$ correlation analysis}

To investigate which gene expression modifications are associated with the methylating properties of NOCs, we performed a correlation analysis considering effects of the three methylating NOCs. $\mathrm{O}^{6}$-meG adducts were measured by HPLC analysis, which revealed a time-dependent decrease in the number of adducts for all three compounds, although NDMA seems to reach a steady-state level between 6 and $24 \mathrm{~h}$ (Fig. 5).

Genes found to significantly correlate $(p$-value $<0.05)$ with $\mathrm{O}^{6}$ meG adducts induced by MNNG, MNU, and NDMA across all time points were analyzed in MetaCore to identify which pathways and processes were most strongly associated with methylation levels. Processes correlated with the level of $\mathrm{O}^{6}$-meG adducts are presented in Table 3, which includes several apoptosis and survival, cell cycle regulation, cytoskeleton remodeling, and DNA damage related pathways. Other strongly modified processes are involved in development, immune response, G-protein signaling, regulation of lipid metabolism, and transcription. The average percentage of genes in these pathways is relatively high, indicating a strong involvement with the methylating damage induced by these compounds. A complete overview of all the pathways involved in these processes can be found in Suppl. Table A.9.

\section{Discussion}

In this study, we investigated NOC-induced gene expression changes at multiple time points in order to identify genes and cellular processes that may change over time, or that might be missed if just one time point is investigated. We hypothesize that in view of their high reactivity nitrosamides induce important gene expression changes relatively early after exposure. These gene expression changes are linked to induced levels of alkylating DNA-damage to

Table 3

Cellular processes correlated with $\mathrm{O}^{6}$-meG levels in DNA as found by MetaCore analysis.

\begin{tabular}{lc}
\hline Cellular process & Correlating pathways \\
\hline Apoptosis and survival & $7(24)$ \\
Cell cycle & $1(21)$ \\
Chemotaxis & $1(25)$ \\
Cytoskeleton remodeling & $2(20)$ \\
Development & $24(26)$ \\
DNA damage & $2(23)$ \\
G-protein signaling & $6(26)$ \\
Immune response & $10(25)$ \\
Neurophysiological process & $3(32)$ \\
Nucleotide metabolism & $1(33)$ \\
Regulation of lipid metabolism & $4(31)$ \\
Riboflavin metabolism & $1(40)$ \\
Signal transduction & $1(29)$ \\
Transcription & $4(26)$ \\
Translation & $1(19)$ \\
\hline
\end{tabular}

Values represent the number of significantly modified pathways for each cellular process followed by the average percentage of significantly modulated genes in these pathways. understand the relevance this type of DNA damage in the carcinogenicity of NOC.

\subsection{Nitrosamide-induced gene expression response}

In the PCA plots (Fig. 1 and Suppl. Figs. A.1-A.3) the nitrosamides shift position over time and always group separately from the nitrosamines with MNNG and MNU uniquely changing the expression of many pathways over time as compared to the nitrosamines (Fig. 2A and Suppl. Tables A.1 and A.2). Although the total average percentage of significantly modulated genes stays relatively constant over time for both nitrosamides (Suppl. Table A.5 and Fig. A.3), the genes modulated after $1 \mathrm{~h}$ of exposure are involved in a higher number of pathways which demonstrates the importance of interpreting data at a functional level. As demonstrated by Fig. 2A and the affected cellular processes per time point (Suppl. Tables A.4-A.7), MNNG and MNU have different transcriptomic effects. Modifications in cell cycle pathways, for example, are observed after $1 \mathrm{~h}$ of MNU exposure, whereas MNNG exposure does not seem to affect the progression of the cell cycle at all. Induction of methyl adducts in DNA by MNU after $1 \mathrm{~h}$ is significantly higher than for MNNG (Fig. 5), which could explain the absence of a cell cycle block following MNNG exposure. In addition, MNU and MNNG induce different protein adducts, either through carbamoylation (MNU) or guanidinylation (MNNG), and histones are known targets for methylation which could differently influence the gene expression profile (Pinsky et al., 1980). Nuclear protein methylation is also known to be induced by alkylating agents (Boffa and Bolognesi, 1985; Boffa et al., 1987) and the level of MNNG-induced methylation (protein or DNA) is determined by intracellular thiol concentrations which could all play an important part in the transcriptomic changes (Jensen and Magee, 1981). It is also interesting that carcinogenic methylating agents methylate proteins in a different pattern than non-carcinogenic methylating agents (Boffa and Bolognesi, 1985). Modifications in apoptosis and cell cycle regulation pathways for MNNG and MNU exposure respectively, are in agreement with flow cytometry data showing a significantly different MNU-induced cell cycle phase distribution at $24 \mathrm{~h}$, whereas MNNG shows a (non-significant) peak in apoptosis at $6 \mathrm{~h}$ (Fig. 4A and $\mathrm{B}$ ). Other modified processes that contribute strongly to the transcriptomic time-course development include development, DNA damage, G-protein signaling, immune response and transcription and as shown by the per time point analysis (Table 1 and Suppl. Tables A.4-A.7), these modifications appear to take place early in the exposure.

Both nitrosamides also modulate a considerable number of pathways involved in developmental processes that regulate cell growth and proliferation, such as the WNT signaling pathway and growth factor/hormone regulated pathways (Suppl. Tables A.4-A.7). These types of modifications are especially interesting for the nitrosamides as the carcinogenicity of these compounds is usually attributed to their DNA damaging capability. Alterations in WNT signaling and growth regulation play an important role in colorectal carcinogenesis (de Lau et al., 2007; Terzic et al., 2010) 


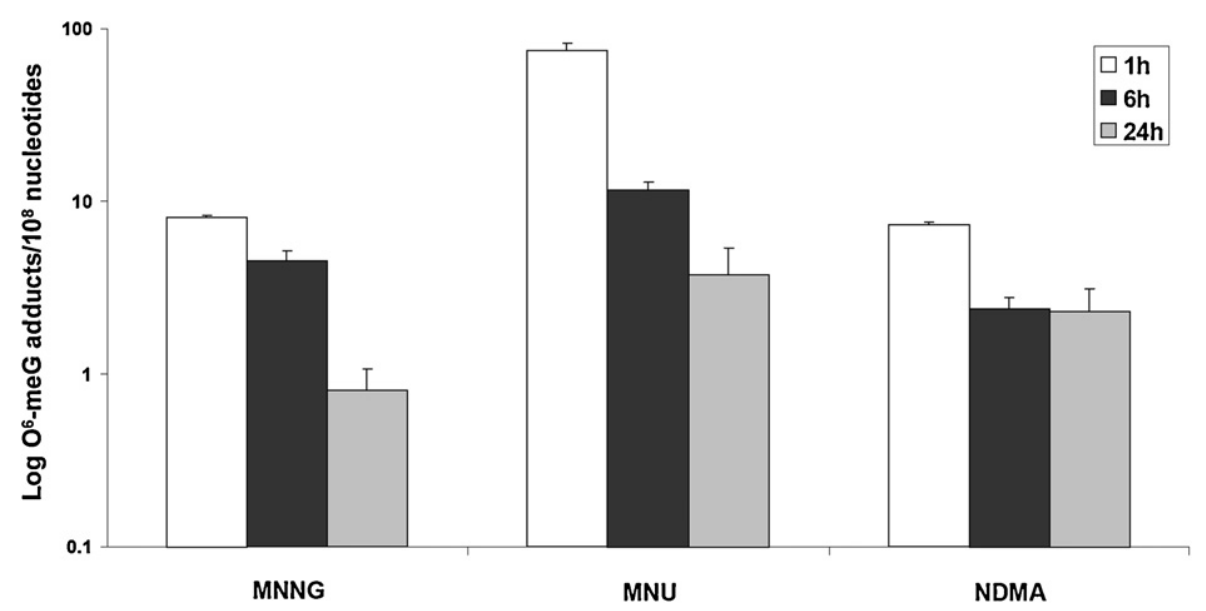

Fig. 5. Level of $\mathrm{O}^{6}-\mathrm{meG}$ in DNA from Caco-2 cells following exposure to genotoxic concentrations of MNNG, MNU or NDMA. Values are corrected for background levels.

and could contribute to cancer development. Additionally, immune response pathways are strongly affected (Table 1 and Suppl. Tables A.4-A.7), including several interleukin and macrophage migration inhibitory factor (MIF) signaling pathways. Nitrosamides have been reported to have immunosuppressive effects (Schoental and Bensted, 1989) and intestinal epithelial cells, including the Caco-2 cell line, excrete pro-inflammatory cytokines and express cytokine receptors (Varilek et al., 1994; Vitkus et al., 1998). Interleukin-6, for example, plays an important role in the induction of the acute phase response and the intestinal inflammatory response (Akira et al., 1993) and also has immunosuppressive properties (Hegde et al., 2004), while MIF is associated with colorectal cancer development (He et al., 2009).

\subsection{Nitrosamine-induced gene expression responses}

The nitrosamines form a separate group in the PCA plot, especially at the 6 and $24 \mathrm{~h}$ time points (Fig. 1), although NDMA shows a deviating response at $24 \mathrm{~h}$. Based on the changes in the percentage of genes and the number of pathways over time (Fig. 3), the strongest response seems to occur after $6 \mathrm{~h}$, although NDMA and NPIP form an exception concerning the number of pathways. One hour of exposure already affects many pathways, although the average percentage of involved genes is considerably lower than at 6 or $24 \mathrm{~h}$. The deviating response of NDMA is most likely due to the 35 uniquely modified pathways found in the ANOVA analysis, which are involved in processes like apoptosis and survival, cell cycle, development, and DNA damage (Fig. 2B and Suppl. Tables A.1 and A.3). These specific processes suggest that the type of DNA damage induced by NDMA plays a role in its response. NDMAinduced methyl adducts are different from the larger alkyl adducts induced by the other nitrosamines, and more efficiently repaired by $\mathrm{O}^{6}$-methylguanine-DNA methyltransferase. This repair activity can be expected to influence cell cycle blockage and apoptosis (Kaina et al., 2007), and compared to the other nitrosamines, NDMA indeed showed the smallest increase in apoptosis and a different cell cycle blockage effect (Fig. 4A and B).

A large number of pathways involved in development are regulated at every time point by the nitrosamines, where nitrosamide-induced modifications are limited to the $1 \mathrm{~h}$ exposure. The response seems to be strongest after 6 and $24 \mathrm{~h}$ since the percentage of involved genes is highest at these time points (Fig. 3). Many of these pathways are differentially regulated over time (Table 1) and include several pathways involved in growth factor signaling and differentiation, such as TGF- $\beta$ and the WNT and Notch signaling pathways (Suppl. Table A.1). From a carcinogenesis perspective, this could be very important as modifications in these pathways could influence the level of differentiation and cell division in the colonic epithelium. The WNT and Notch signaling pathways, for example, are known to interact in the maintenance of progenitor cell populations in the colon (de Lau et al., 2007). It seems that both nitrosamines and nitrosamides are capable of modifying essential developmental processes, which could work in concert with the DNA damaging capabilities of NOCs in the carcinogenic process.

Nitrosamine exposure also strongly affects the immune response as demonstrated by the large number of pathways involved in this process (Table 1 and Suppl. Tables A.1 and A.4-A.7). Although the nitrosamides also affected the immune response throughout the exposure period, the nitrosamineinduced response is much stronger, especially at 6 and $24 \mathrm{~h}$, with more involved pathways and a higher percentage of modulated genes. Nitrosamines have immunosuppressive effects (Haggerty and Holsapple, 1990) and this may influence the innate immune response of colonic epithelial cells. Since the immune response also plays an important role in the development of colon cancer, especially in the promotion phase of the carcinogenic process, this indicates an additional way for nitrosamines to influence colon cancer risk (Terzic et al., 2010). As shown in Suppl. Tables A.5-A.7, several cytokine signaling pathways, such as MIF and interleukin-1, $6,12,22$ and 27 signaling are modified, many of which are implicated in colon cancer development (He et al., 2009; Terzic et al., 2010). The four nitrosamines do not always affect the same pathways and the net effect on immune modulation may not always be the same for all nitrosamines. Nevertheless, the PCA plots imply that especially NDEA, NPIP, and NPYR induce a similar response. Our findings demonstrate the relevance of further research into the immunomodulatory properties of NOCs.

Other interesting observations are the modifications in pathways involved in regulation of lipid metabolism, cystic fibrosis, and steroid metabolism which are regulated at all time points, although not for every nitrosamine (Suppl. Tables A.5-A.7). Lipid metabolism regulation could be associated with the apoptotic process (Zhou et al., 2003), but it may also play a part in the cystic fibrosis process. The pathways belonging to this process are involved in ion channel conductance regulation and lipid synthesis and transportation and are known to play a very important role in intestinal fluid and ion concentration regulation (Mailhot et al., 2009). The steroid metabolism pathways could be explained in the context of nitrosamine metabolism which is known to be influenced by steroid signaling pathways (Ahir and Mohla, 1989). 


\subsection{Phenotypic anchoring of apoptosis and cell cycle effects}

The ANOVA and time point analyses of NOC-induced gene expression modifications confirm the changes in levels of apoptosis and cell cycle distribution found by flow cytometry for both the nitrosamides and nitrosamines which already shows that a time series analysis of transcriptomic data can reflect the phenotypic effects of NOC exposure. The association between the flow cytometry results and the apoptosis and cell cycle regulation processes is further confirmed by a correlation analysis (Table 2, Suppl. Table A.8), which shows that genes significantly correlating with apoptosis or cell cycle phase distribution are, in turn, involved in these very same processes and closely related processes like cell adhesion, cytoskeleton remodeling, nucleotide metabolism, and proteolysis.

\subsection{Methylation-related gene expression modulations}

Since there are indications that methylating damage may influence the gene expression response, this could contribute to the carcinogenic effect associated with this type of damage. Guanine methyl adducts, and possibly others, can influence transcription factor binding and the action of maintenance methylases on adjacent cytosine bases, which could both have important consequences for gene expression modifications in relation to carcinogenesis (Bonfanti et al., 1991; Gray, 1995; Hepburn et al., 1991; Tan and $\mathrm{Li}, 1990)$.

The analysis of $\mathrm{O}^{6}$-meG levels shows that NDMA induces a relatively low level of methylation compared to the nitrosamides which is somewhat surprising, especially since the concentration of NDMA used in this study is much higher than for the nitrosamides. Animal studies have shown that NDMA is by far the most efficient agent capable of generating $\mathrm{O}^{6}$-meG in blood cell DNA when compared with other known methylating agents, such as MNU (Souliotis et al., 1995; Valavanis et al., 1994). However, this does not seem to be true for Caco-2 cells since we found MNU to be the most efficient methylating agent, while MNNG generated methyl adducts at approximately the same level as NDMA (Fig. 5). Since the alkylating properties of nitrosamines are dependent on their metabolic activation by CYP450, this will influence the formation of $\mathrm{O}^{6}$-meG adducts. Although Caco-2 cells and the human colon are both known to express CYP enzymes involved in nitrosamine metabolism (Bergheim et al., 2005; Borlak and Zwadlo, 2003), this is lower than in, for example, liver tissue. A combination of the CYP450-dependent biotransformation and higher stability of nitrosamines allows for a longer continuous exposure which is likely to influence gene expression more extensively and explain the transcriptomic difference between nitrosamines and nitrosamides found in this study. The decrease in $0^{6}$-meG adducts following NDMA exposure indeed levels out between 6 and $24 \mathrm{~h}$ suggesting a continuous formation of reactive diazonium ions, whereas both nitrosamides show an incessant decrease over time.

A correlation analysis of transcriptomics results across all time points reveals a number of processes that are associated with methylation induced by MNNG, MNU, and NDMA (Table 3). Apoptosis and survival, cell cycle regulation and related processes, such as cytoskeleton remodeling and nucleotide metabolism, are involved and would also be expected to be associated with methylation levels, since this type of damage is a well-known inducer of apoptosis accompanied by cell cycle blockage and cytoskeleton modifications (Kaina et al., 2007). DNA damage pathways are associated with methylation levels as well. The results also suggest that methylation levels influence development, G-protein signaling and the immune response, since many pathways are involved in these processes. Especially development is strongly represented and includes many pathways involved in growth factor signaling often involving the JAK-STAT cascade, while the G-protein signaling process includes a number of RAS signaling pathways (Suppl. Table A.9). These pathways are implicated in the carcinogenic process and it is possible that the modifications in these pathways represent an epigenetic component of methylation-associated gene expression changes, thereby providing a way to influence crucial carcinogenic mechanisms in parallel to the genotoxic mode of action (Smirnova et al., 2007; Takayama et al., 2006; Wu et al., 2010). Whether other types of alkylation, such as adducts induced by NDEA, NPIP, and NPYR, are also linked to gene expression modifications is not known, but would be worth investigating.

It is an interesting observation that MNU, which causes the highest $\mathrm{O}^{6}$-meG levels after $1 \mathrm{~h}$ of exposure, also affects the highest number of pathways at this time point (Fig. 3). In general, the timedependent decrease in methylation level induced by these three investigated compounds is paralleled by a decrease in the number of significantly modulated pathways. Although the processes found in the correlation analysis were also found in the ANOVA and per time point analyses, the pathways involved in each of the processes are not always the same or not that strongly represented for the individual compounds in the time point analysis (see Suppl. Tables A.1 and A.5-A.7). Especially the nitrosamides are not strongly involved in some of the processes found in the correlation analyses, such as the apoptosis and DNA repair processes. This may be a result of the filtering criterion used in the time point analysis, whereas the correlation analyses uses all significantly correlating genes regardless of $\log 2$ ratio or $p$-value per time point. The pathways found in the correlation analyses, which combines all time points in the analysis, therefore probably represent a more subtle effect that is difficult to pick up per time point.

\subsection{Correspondence to in vivo situation}

Interpretation of the transcriptomic results in terms of in vivo CRC risk following exposure to NOCs should be done with considerable restraints. Aside from the obvious limitation of comparing a cell line model to an in vivo organ, the concentrations used in this study are also rather high as compared to what is normally found in the colon. In vivo NOC exposures as a result of endogenous nitrosation can reach micromolar levels in the colon lumen (Lunn et al., 2007), which is considerably lower than the millimolar concentrations of nitrosamines that were used in this study. Although the applied nitrosamide concentrations are in the micromolar range, reliable data on nitrosamide concentrations in the colon lumen are lacking, making it difficult to make a good in vivo-in vitro comparison. In addition, in vivo exposures occur over a much longer time frame at varying concentrations, which could also result in different effects. In this context it is, however, reassuring that we recently identified transcriptomic responses that correlate with in vivo NOC exposure and that match some of our results here. These responses include modifications in pathways related to the DNA damage response, apoptosis and survival, and the immune response (Hebels et al., 2011a,b). This indicates that the in vitro results found here can indeed provide valuable insights into the toxicological properties of NOCs using transcriptomics.

\subsection{Conclusions}

In summary, we have found that NOC-induced gene expression changes vary over time and that nitrosamides induce the strongest response within $1 \mathrm{~h}$ after onset of the exposure. Many of the pathways and processes modified may indicate a carcinogenic risk associated with NOC exposure since they involve pathways implicated in crucial developmental signaling cascades. Methylation is also associated with processes that could contribute to the carcinogenic risk following colonic NOC exposure, suggesting that methylating mechanisms can play a role in the carcinogenic 
process through gene expression modulations. Further research is needed to determine if these modifications also play a role in cancer development in the human colon, preferably in an in vivo setting focusing on endogenous nitrosation processes. This would overcome some of the limitations of this study, such as the rather high exposure concentrations compared to what can be expected in vivo and the relative simplicity of a cell line compared to much more complex colon tissue. Nevertheless, the temporal transcriptomic responses discovered here give a more detailed overview of the possible mechanisms of action of NOCs and provide new topics of research into the carcinogenic properties of these compounds in humans.

\section{Role of the funding source}

This study was internally funded by Maastricht University. The funding source was not involved in any way in the conduct of the research and/or preparation of the article.

\section{Conflict of interest statement}

The authors declare that there are no conflicts of interest.

\section{Appendix A. Supplementary data}

Supplementary data associated with this article can be found, in the online version, at doi:10.1016/j.toxlet.2011.09.012.

\section{References}

Ahir, S., Mohla, S., 1989. Regulation of renal N-nitrosodimethylamine demethylase activity by androgens, progestin, glucocorticoid, and estrogen in BALB/c mice. Cancer Res. 49, 3737-3741.

Akira, S., Taga, T., Kishimoto, T., 1993. Interleukin-6 in biology and medicine. Adv. Immunol. 54, 1-78.

Bergheim, I., Bode, C., Parlesak, A., 2005. Distribution of cytochrome P450 2C, 2E1, $3 \mathrm{~A} 4$, and $3 \mathrm{~A} 5$ in human colon mucosa. BMC Clin. Pharmacol. 5, 4.

Boffa, L.C., Bolognesi, C., 1985. Nuclear proteins damage by alkylating agents with different degrees of carcinogenicity. Chem. Biol. Interact. 55, 235-245.

Boffa, L.C., Bolognesi, C., Mariani, M.R., 1987. Specific targets of alkylating agents in nuclear proteins of cultured hepatocytes. Mutat. Res. 190, 119-123.

Bonfanti, M., Broggini, M., Prontera, C., D’Incalci, M., 1991. O6-methylguanine inhibits the binding of transcription factors to DNA. Nucleic Acids Res. 19, 5739-5742.

Borlak, J., Zwadlo, C., 2003. Expression of drug-metabolizing enzymes, nuclear transcription factors and ABC transporters in Caco-2 cells. Xenobiotica 33, 927-943.

de Lau, W., Barker, N., Clevers, H., 2007. WNT signaling in the normal intestine and colorectal cancer. Front. Biosci. 12, 471-491.

Georgiadis, P., Kaila, S., Makedonopoulou, P., Fthenou, E., Chatzi, L., Pletsa, V., Kyrtopoulos, S.A., 2011. Development and validation of a new, sensitive immunochemical assay for O-methylguanine in DNA and its application in a population study. Cancer Epidemiol. Biomarkers Prev. 20, 82-90.

Georgiadis, P., Samoli, E., Kaila, S., Katsouyanni, K., Kyrtopoulos, S.A., 2000. Ubiquitous presence of O6-methylguanine in human peripheral and cord blood DNA. Cancer Epidemiol. Biomarkers Prev. 9, 299-305.

Gray, P.J., 1995. Sulphur mustards inhibit binding of transcription factor AP2 in vitro. Nucleic Acids Res. 23, 4378-4382.

Haggerty, H.G., Holsapple, M.P., 1990. Role of metabolism in dimethylnitrosamineinduced immunosuppression: a review. Toxicology 63, 1-23.

Hall, J., Montesano, R., 1990. DNA alkylation damage: consequences and relevance to tumour production. Mutat. Res. 233, 247-252.

He, X.X., Chen, K., Yang, J., Li, X.Y., Gan, H.Y., Liu, C.Y., Coleman, T.R., Al-Abed, Y., 2009. Macrophage migration inhibitory factor promotes colorectal cancer. Mol. Med. $15,1-10$.

Hebels, D.G., Jennen, D.G., Kleinjans, J.C., de Kok, T.M., 2009. Molecular signatures of $\mathrm{N}$-nitroso compounds in Caco-2 cells: implications for colon carcinogenesis. Toxicol. Sci. 108, 290-300.

Hebels, D.G., Jennen, D.G., van Herwijnen, M.H., Moonen, E.J., Pedersen, M., Knudsen, L.E., Kleinjans, J.C., de Kok, T.M., 2011a. Whole-genome gene expression modifications associated with nitrosamine exposure and micronucleus frequency in human blood cells. Mutagenesis.

Hebels, D.G., Sveje, K.M., de Kok, M.C., van Herwijnen, M.H., Kuhnle, G.G., Engels, L.G., Vleugels-Simon, C.B., Mares, W.G., Pierik, M., Masclee, A.A., Kleinjans, J.C., de Kok, T.M., 2011b. N-nitroso compound exposure-associated transcriptomic profiles are indicative of an increased risk for colorectal cancer. Cancer Lett. 309, $1-10$.
Hegde, S., Pahne, J., Smola-Hess, S., 2004. Novel immunosuppressive properties of interleukin- 6 in dendritic cells: inhibition of NF-kappaB binding activity and CCR7 expression. FASEB J. 18, 1439-1441.

Hepburn, P.A., Margison, G.P., Tisdale, M.J., 1991. Enzymatic methylation of cytosine in DNA is prevented by adjacent O6-methylguanine residues. J. Biol. Chem. 266 7985-7987.

Jensen, D.E., Magee, P.N., 1981. Methylation of DNA by nitrosocimetidine in vitro. Cancer Res. 41, 230-236.

Kaina, B., Christmann, M., Naumann, S., Roos, W.P., 2007. MGMT: key node in the battle against genotoxicity, carcinogenicity and apoptosis induced by alkylating agents. DNA Repair (Amst.) 6, 1079-1099.

Kuhnle, G.G., Bingham, S.A., 2007. Dietary meat, endogenous nitrosation and colorectal cancer. Biochem. Soc. Trans. 35, 1355-1357.

Kyrtopoulos, S.A., 1998. DNA adducts in humans after exposure to methylating agents. Mutat. Res. 405, 135-143.

Larsson, S.C., Wolk, A., 2006. Meat consumption and risk of colorectal cancer: a meta-analysis of prospective studies. Int. J. Cancer 119, 2657-2664.

Lijinsky, W., 1992. Chemistry and Biology of N-nitroso Compounds. Cambridge Univ. Press, Cambridge, UK.

Lunn, J.C., Kuhnle, G., Mai, V., Frankenfeld, C., Shuker, D.E., Glen, R.C., Goodman, J.M., Pollock, J.R., Bingham, S.A., 2007. The effect of haem in red and processed meat on the endogenous formation of $\mathrm{N}$-nitroso compounds in the upper gastrointestinal tract. Carcinogenesis 28, 685-690.

Mailhot, G., Ravid, Z., Barchi, S., Moreau, A., Rabasa-Lhoret, R., Levy, E., 2009. CFTR knockdown stimulates lipid synthesis and transport in intestinal Caco-2/15 cells. Am. J. Physiol. Gastrointest. Liver Physiol. 297, G1239-G1249.

Mirvish, S.S., 1995. Role of N-nitroso compounds (NOC) and N-nitrosation in etiology of gastric, esophageal, nasopharyngeal and bladder cancer and contribution to cancer of known exposures to NOC. Cancer Lett. 93, 17-48.

Mosmann, T., 1983. Rapid colorimetric assay for cellular growth and survival: application to proliferation and cytotoxicity assays. J. Immunol. Methods 65 55-63.

Norat, T., Lukanova, A., Ferrari, P., Riboli, E., 2002. Meat consumption and colorectal cancer risk: dose-response meta-analysis of epidemiological studies. Int. J. Cancer 98, 241-256.

Paraskeva, C., Corfield, A.P., Harper, S., Hague, A., Audcent, K., Williams, A.C., 1990 Colorectal carcinogenesis: sequential steps in the in vitro immortalization and transformation of human colonic epithelial cells. Anticancer Res. 10, 1189-1200 (review).

Pinsky, S.D., Lee, K.E., Woolley 3rd, P.V., 1980. Uptake and binding of 1-methyl-1nitrosourea (MNU) and 1-methyl-3-nitro-1-nitrosoguanidine (MNNG) by the isolated guinea pig pancreas. Carcinogenesis 1, 567-575.

Schoental, R., Bensted, J.P.M., 1989. Immunotoxicity of n-nitrosamides: acute lesions and neoplasias of the lungs, the lymphoid system and of the gastro-intestinal tract. Int. J. Environ. Stud. 33, 213-219.

Schutte, B., Henfling, M., Ramaekers, F.C., 2006. DEDD association with cytokeratin filaments correlates with sensitivity to apoptosis. Apoptosis 11, 1561-1572.

Sen, N.P., Seaman, S.W., Burgess, C., Baddoo, P.A., Weber, D., 2000. Investigation on the possible formation of $\mathrm{N}$-nitroso- $\mathrm{N}$-methylurea by nitrosation of creatinine in model systems and in cured meats at gastric pH. J. Agric. Food Chem. 48 5088-5096.

Shi, L., Reid, L.H., Jones, W.D., Shippy, R., Warrington, J.A., Baker, S.C., Collins, P.J., de Longueville, F., Kawasaki, E.S., Lee, K.Y., Luo, Y., Sun, Y.A., Willey, J.C., Setterquist, R.A., Fischer, G.M., Tong, W., Dragan, Y.P., Dix, D.J., Frueh, F.W., Goodsaid, F.M., Herman, D., Jensen, R.V., Johnson, C.D., Lobenhofer, E.K., Puri, R.K., Schrf, U., Thierry-Mieg, J., Wang, C., Wilson, M., Wolber, P.K., Zhang, L., Amur, S., Bao, W., Barbacioru, C.C., Lucas, A.B., Bertholet, V., Boysen, C., Bromley, B., Brown, D. Brunner, A., Canales, R., Cao, X.M., Cebula, T.A., Chen, J.J., Cheng, J., Chu, T.M., Chudin, E., Corson, J., Corton, J.C., Croner, L.J., Davies, C., Davison, T.S., Delenstarr, G., Deng, X., Dorris, D., Eklund, A.C., Fan, X.H., Fang, H., Fulmer-Smentek, S., Fuscoe, J.C., Gallagher, K., Ge, W., Guo, L., Guo, X., Hager, J., Haje, P.K., Han, J., Han, T., Harbottle, H.C., Harris, S.C., Hatchwell, E., Hauser, C.A., Hester, S., Hong, H., Hurban, P., Jackson, S.A., Ji, H., Knight, C.R., Kuo, W.P., LeClerc, J.E., Levy, S., Li, Q.Z., Liu, C., Liu, Y., Lombardi, M.J., Ma, Y., Magnuson, S.R., Maqsodi, B., McDaniel, T., Mei, N., Myklebost, O., Ning, B., Novoradovskaya, N., Orr, M.S. Osborn, T.W., Papallo, A., Patterson, T.A., Perkins, R.G., Peters, E.H., Peterson, R. Philips, K.L., Pine, P.S., Pusztai, L., Qian, F., Ren, H., Rosen, M., Rosenzweig, B.A., Samaha, R.R., Schena, M., Schroth, G.P., Shchegrova, S., Smith, D.D., Staedtler, F., Su, Z., Sun, H., Szallasi, Z., Tezak, Z., Thierry-Mieg, D., Thompson, K.L., Tikhonova, I., Turpaz, Y., Vallanat, B., Van, C., Walker, S.J., Wang, S.J., Wang, Y., Wolfinger, R., Wong, A., Wu, J., Xiao, C., Xie, Q., Xu, J., Yang, W., Zhang, L., Zhong, S., Zong, Y., Slikker Jr., W., 2006. The MicroArray Quality Control (MAQC) project shows inter- and intraplatform reproducibility of gene expression measurements. Nat. Biotechnol. 24, 1151-1161.

Shrivastav, N., Li, D., Essigmann, J.M., 2010. Chemical biology of mutagenesis and DNA repair: cellular responses to DNA alkylation. Carcinogenesis 31, 59-70.

Smirnova, O.V., Ostroukhova, T.Y., Bogorad, R.L., 2007. JAK-STAT pathway in carcinogenesis: is it relevant to cholangiocarcinoma progression? World J. Gastroenterol. 13, 6478-6491.

Souliotis, V.L., Chhabra, S., Anderson, L.M., Kyrtopoulos, S.A., 1995. Dosimetry of 06-methylguanine in rat DNA after low-dose, chronic exposure to Nnitrosodimethylamine (NDMA). Implications for the mechanism of NDMA hepatocarcinogenesis. Carcinogenesis 16, 2381-2387.

Takayama, T., Miyanishi, K., Hayashi, T., Sato, Y., Niitsu, Y., 2006. Colorectal cancer: genetics of development and metastasis. J. Gastroenterol. 41, 185-192. 
Tan, N.W., Li, B.F., 1990. Interaction of oligonucleotides containing 6-Omethylguanine with human DNA (cytosine-5-)-methyltransferase. Biochemistry (Mosc.) 29, 9234-9240 [published erratum appears in Biochemistry 1992 Aug 4;31(30):7008].

Terzic, J., Grivennikov, S., Karin, E., Karin, M., 2010. Inflammation and colon cancer. Gastroenterology 138, 2101-2114 e2105.

Tricker, A.R., Preussmann, R., 1991. Carcinogenic N-nitrosamines in the diet: occurrence, formation, mechanisms and carcinogenic potential. Mutat. Res. 259, 277-289.

Valavanis, C., Souliotis, V.L., Kyrtopoulos, S.A., 1994. Differential effects of procarbazine and methylnitrosourea on the accumulation of O6-methylguanine and the depletion and recovery of O6-alkylguanine-DNA alkyltransferase in rat tissues. Carcinogenesis 15, 1681-1688.
Varilek, G.W., Neil, G.A., Bishop, W.P., 1994. Caco-2 cells express type I interleukin1 receptors: ligand binding enhances proliferation. Am. J. Physiol. 267, G1101-G1107.

Vitkus, S.J., Hanifin, S.A., McGee, D.W., 1998. Factors affecting Caco-2 intestinal epithelial cell interleukin-6 secretion. In Vitro Cell. Dev. Biol. Anim. 34, 660-664.

Wu, C.H., Shih, Y.W., Chang, C.H., Ou, T.T., Huang, C.C., Hsu, J.D., Wang, C.J., 2010. EP4 upregulation of Ras signaling and feedback regulation of Ras in human colon tissues and cancer cells. Arch. Toxicol. 84, 731-740.

Zhou, W., Simpson, P.J., McFadden, J.M., Townsend, C.A., Medghalchi, S.M., Vadlamudi, A., Pinn, M.L., Ronnett, G.V., Kuhajda, F.P., 2003. Fatty acid synthase inhibition triggers apoptosis during $\mathrm{S}$ phase in human cancer cells. Cancer Res. 63, 7330-7337. 